\title{
GESTÃo ESTRATÉGICA DE PESSOAS PARA PESQUISADORES EM ADMINISTRAÇÃO NAS UNIVERSIDADES PRIVADAS
}

\author{
Paschoal Palombino Primo \\ primorh@terra.com.br \\ Universidade Municipal de São Caetano do Sul- SP / Brasil \\ Eduardo de Camargo Oliva \\ eduardo.oliva@uscs.edu.br \\ Universidade Municipal de São Caetano do Sul- SP / Brasil \\ Edson Keyso de Miranda Kubo \\ edsonkubo@uscs.edu.br \\ Universidade Municipal de São Caetano do Sul- SP / Brasil
}

http://dx.doi.org/10.1590/1413-2311063201238442

Recebido em 03/10/2013

Aprovado em 04/10/2013

Disponibilizado em 01/08/2014

Avaliado pelo sistema double blind review

Revista Eletrônica de Administração

Editor: Luís Felipe Nascimento

ISSN 1413-2311 (versão on-line)

Editada pela Escola de Administração da Universidade Federal do Rio Grande do Sul. Periodicidade: Quadrimestral

Sistema requerido: Adobe Acrobat Reader.

\section{RESUMO}

Esta pesquisa objetivou a descrever e analisar as políticas e/ou práticas de Gestão de Pessoas das Instituições Privadas de Ensino Superior da região metropolitana da Grande São Paulo, para os docentes pesquisadores dos cursos de Administração Stricto Sensu. Trata-se de um estudo exploratório e qualitativo, em que foram pesquisadas oito instituições, tendo como atores os responsáveis pela gestão dos cursos de Administração Stricto Sensu, os responsáveis pelas áreas de $\mathrm{RH}$ e os docentes pesquisadores, totalizando 30 entrevistas. Utilizou-se a técnica de análise de conteúdo com auxílio do Atlas TI 6.2. Verificou-se que as políticas e/ou práticas estratégicas de gestão de pessoas existentes nas instituições pesquisadas, revelaram-se pouco convincentes à luz das abordagens teóricas referenciadas no presente estudo. As ações estratégicas deliberadas para os programas de Pós-Graduação Stricto Sensu em Administração das IES pesquisadas seguem objetivos oriundos do ambiente externo, sem existência de um planejamento estratégico de gestão de pessoas que considere o pesquisador como elemento central. No entanto, observaram-se algumas práticas de gestão de pessoas que sinalizam como sendo contributivas e diferenciadas das práticas gerais observadas, tais como atração, retenção e desenvolvimento dos docentes pesquisadores.

Palavras-chave: Gestão Estratégica de Pessoas; Universidades Privadas; Pós-Graduação em Administração; Pesquisadores. 
Gestão estratégica de pessoas para pesquisadores em administração nas universidades privadas

\title{
STRATEGIC PEOPLE MANAGEMENT FOR RESEARCHES IN BUSINESS ADMINISTRATION IN BRAZILIAN UNIVERSITIES
}

\begin{abstract}
This study aimed to describe and analyze the policies and/or practices of people management in private institutions of higher education in the metropolitan region of Sao Paulo for research professors from the Graduate Courses of Management. This is an exploratory and qualitative study, in which eight institutions were surveyed and it approached the actors responsible for the Management of Graduate Courses in Business Administration, those in charge of HR and the research professor, totalizing 30 interviews. It used techniques of content analysis with the support of the Atlas IT 6.2. It was verified that the policies and/or practices of people management in the institutions surveyed seemed to be unconvincing in the light of the theoretical approaches referenced in this study. The deliberated strategic means for the Graduate Courses in Business Administration in this research follow objectives from the external environment without the concern for a strategic planning in people management that consider the researcher as the central element. However, it was observed that some people management's practices seemed to be contributive and distinguished from observed general practices such as attraction, retention and development of research professors.
\end{abstract}

Keywords: Strategic People Management; Private Universities; Graduate in Business Administration; Researchers.

\section{GESTIÓN ESTRATÉGICA DE PERSONAS PARA INVESTIGADORES EN ADMINISTRACIÓN DE EMPRESAS EN LAS UNIVERSIDADES PRIVADAS}

\begin{abstract}
RESUMEN
Este estudio tuvo como objetivo describir y analizar las políticas y / o prácticas de Administración de Personal de Instituciones Privadas de Educación Superior en la región metropolitana de São Paulo, para los investigadores de cursos stricto sensu de la facultad de administración. Se trata de un estudio exploratorio y cualitativo en el que se encuestó a ocho instituciones, con los actores responsables de la gestión de los cursos de Administración stricto sensu, con los responsables de recursos humanos y con los profesores investigadores, por un total de 30 entrevistas. Se utilizó la técnica de análisis de contenido con la ayuda de Atlas TI 6.2. Se encontró que las políticas y / o prácticas de gestión estratégica de personas existentes en las instituciones encuestadas han resultado poco convincentes a la luz de los enfoques teóricos que se hace referencia en este estudio. Las acciones estratégicas deliberadas para los programas de pós-grado Stricto Sensu en Administración de las IES encuestadas siguen objetivos procedentes del ambiente externo, sin la existencia de un plan estratégico para la gestión de las personas que consideran el investigador como elemento central. Sin embargo, se han observado algunas prácticas de gestión de personas que señalan como siendo contributivas y diferenciadas de las prácticas generales observadas, tal como la atracción, retención y desarrollo de profesores investigadores.
\end{abstract}

REAd | Porto Alegre - Edição 78 - Nº 2 - maio/agosto 2014 - p. 371-396 
Paschoal Palombino Primo, Eduardo de Camargo Oliva \& Edson Keyso de Miranda Kubo

Palabras Clave: Gestión Estratégica de Personas; Instituciones Privadas; Estudios de Postgrado en Administración de Empresas; Investigadores.

\section{INTRODUÇÃO}

As organizações contemporâneas exigem cada vez mais que a gestão de pessoas esteja estrategicamente alinhada aos objetivos de seus negócios. O capital humano tem sido o diferencial competitivo para o sucesso das organizações, pois é dele que surgem as inspirações para o pensamento, seja ao nível tático, estratégico ou operacional. Há um crescente reconhecimento da importância do capital humano nas organizações que devido a sua complexidade e diversidade, precisa ser gerida, liderada e dirigida (BARRETO; COSTA, 2010; BARNEY, 1991).

Para Leite e Albuquerque (2009), a formulação da missão e dos objetivos da organização, assim como de políticas e planos de ação, leva em consideração os impactos das forças do ambiente. Sob esse contexto, o enfoque da gestão estratégica de pessoas pode ser entendido por meio do contrato psicológico entre os indivíduos e as organizações.

Gerir pessoas se tornou um desafio de muitas organizações, quando visam a assegurar o comprometimento e o desenvolvimento do ativo humano para a implementação de objetivos estratégicos e busca de melhores resultados. É um processo complexo que deve ser arquitetado (BIANCHI, 2008).

Para Armstrong (2009), a gestão de pessoas integrada aos valores organizacionais pode contribuir para que objetivos e metas das organizações sejam alcançados. Neste sentido, exigem-se das organizações que, estratégias, políticas e práticas de gestão de pessoas sejam elaboradas, assim como o desenvolvimento de estruturas que sejam capazes de contribuir com o processo de gestão. O estágio de profissionalização em que se encontram as organizações é um fator relevante a ser considerado para o entendimento das pressões acarretadas pelo ambiente competitivo (SILVA; FONSECA, 2010).

Assim, nas universidades privadas, objeto do presente estudo, há de se verificar a necessidade de uma política de gestão de pessoas que contemple o conjunto das funções existentes na estrutura organizacional em todos os níveis, sejam eles, operacionais, técnicos, administrativos e acadêmicos.

Para Garcia (2006), não obstante o reconhecimento da importância dos valores humanos nas instituições de ensino superior, em que os docentes representam o principal elo na cadeia

REAd | Porto Alegre - Edição 78 - № 2 - maio/agosto 2014 - p. 371-396 
Gestão estratégica de pessoas para pesquisadores em administração nas universidades privadas

de prestação de serviço, usualmente o setor de Recursos Humanos não se ocupa com ações de valorização do capital humano, mas com as questões burocráticas da administração de pessoal tais como emissão de folha de pagamento, controle de férias, entre outras de ordem legais.

São raras as instituições de ensino superior nas quais o setor de Recursos Humanos assume uma postura estratégica comprometida de fato com a agregação de valor ao processo educacional, através de consistentes programas de avaliação, certificação e capacitação docente (GARCIA, 2006).

Grillo (2001) considera que a gestão de pessoas deve levar em conta a especificidade da instituição de ensino superior IES e de seu quadro funcional e incluir todas as categorias tais como professores, pesquisadores, técnicos e administradores como importantes e relevantes na busca do sucesso da instituição, visando a um tratamento igualitário no estabelecimento de normas, incentivos e no desenvolvimento profissional e pessoal desses colaboradores.

Estudos feitos por Kiste (2001) e Bernardes (2003) apontam para a gestão de pessoas com ênfase ao corpo técnico-administrativo das IES, mas não tratam da gestão estratégica de pessoas para os docentes pesquisadores.

Para Kiste (2001), o crescimento das instituições de ensino superior privadas é algo que não passa despercebido pela sociedade brasileira e, como uma das decorrências desses fenômenos, cresce a preocupação com as questões relacionadas à gestão desse tipo de organização.

Estudo de caso feito por Santos (2010), em uma Instituição de Ensino Superior Confessional, não lucrativa, situada no Vale do Paraíba (SP), quanto às práticas para gerir os docentes diante de um cenário globalizado competitivo, constatou que esse tipo de instituição ainda não possui uma política clara para gerir seu corpo docente, mas está se estruturando para elaborá-la.

O interesse pelo tema deve-se à relevância que a Gestão Estratégica de Pessoas (GEP) assume no cenário competitivo atual e à importância da função do docente no contexto da instituição de ensino superior, da sociedade brasileira e da comunidade científica nacional e internacional. O objetivo deste artigo é descrever e analisar as políticas e/ou práticas de Gestão de Pessoas das Instituições Privadas de Ensino Superior da região metropolitana da Grande São Paulo e, exclusivamente para os docentes pesquisadores que integram os programas de pós-graduação Stricto Sensu em Administração. Os programas de pósgraduação em Administração estão inseridos na Grande área de Ciências Sociais Aplicadas da 
Paschoal Palombino Primo, Eduardo de Camargo Oliva \& Edson Keyso de Miranda Kubo

CAPES. Constata-se que apenas no Estado de São Paulo ela representa 29,48\% dos mestres, doutores e mestres profissionais titulados em relação ao total de titulados no Brasil (CAPES, 2011). Outra motivação decorreu da concentração de IES com personalidade jurídica privada na região metropolitana de São Paulo que possibilitaria o acesso à coleta de dados.

\section{GESTÃo ESTRATÉGICA DE PESSOAS}

A abordagem estratégica de Recursos Humanos surgiu no início da década de 80, com a inserção do papel dos Recursos Humanos no planejamento estratégico da organização (BOSQUETTI; ALBUQUERQUE, 2005). Assim, iniciou-se o alinhamento entre a gestão de pessoas e as estratégias organizacionais. Na visão de Bohlander e Snell (2009), a Gestão de Pessoas assumiu papel estratégico, uma vez que as pessoas são relevantes na construção das competências organizacionais e obtenção de resultados por serem produtoras de conhecimento e inovação, elementos primordiais para a capacitação organizacional.

Segundo Boxal, Pucell e Wright (2010), duas vertentes de análises devem ser consideradas quando se trata da gestão de pessoas: questionar o desempenho relativo dos modelos específicos de gestão de recursos humanos em contextos particulares ou da sua contribuição para um melhor desempenho organizacional em relação a outros investimentos organizacionais, tais como novas tecnologias de produção, campanhas publicitárias e aquisições de propriedade; questionar a necessidade do processo de gestão de recursos humanos em si, como e se as organizações poderiam de alguma forma sobreviver ou crescer sem fazer uma tentativa razoável de organização do trabalho e gestão de pessoas.

A Gestão Estratégica leva em consideração a visão dos atores organizacionais responsáveis pelas estratégias e deve considerar a análise do ambiente organizacional (QUEIROZ; ALBUQUERQUE, 2009). Essa abordagem supõe a análise de cenários internos e externos, ameaças e oportunidades, os quais estão constantemente impondo mudanças às organizações e consequentemente às pessoas que nelas trabalham. Queiroz e Albuquerque (2009) também ressaltam que a essas mudanças internas, devem-se somar as externas, que forçam as pessoas a se manterem conectadas com os mercados nos quais atuam e também em mercados complementares no sentido de estarem atentas às análises de novas tecnologias, custos, preços, produtos, qualidade, enfim, às exigências dos clientes e à pressão dos

concorrentes. A Gestão Estratégica de Pessoas vem se constituindo em fator de 
Gestão estratégica de pessoas para pesquisadores em administração nas universidades privadas

competitividade para as organizações, em especial, quando suas práticas atingem elevado grau de alinhamento com os objetivos da organização.

Para Barreto e Costa (2010), o pressuposto que subsidia a Gestão Estratégica de Pessoas consiste na ideia de que o desempenho organizacional é influenciado por um conjunto de práticas de gestão de pessoas. Assim, a Gestão Estratégica de Pessoas tem a capacidade de aumentar a vantagem competitiva organizacional. Portanto, atrair e reter talentos, formar, estimular a motivação e o comprometimento das pessoas, requer políticas que objetivem à integração de ações práticas da área para o alcance de resultados. Nessa linha, novos desafios são impostos com frequência aos gestores organizacionais tais como modificar a maneira como a função de Recursos Humanos é vista dentro das empresas e planejar as transformações necessárias para o alinhamento estratégico das pessoas aos objetivos estratégicos da empresa. De acordo com Bosquetti (2009), a gestão estratégica de pessoas tem a ver com as contribuições das decisões, políticas, estratégias e práticas de gestão de pessoas para efetividade organizacional e de que forma tais contribuições são alcançadas.

Para Queiroz e Albuquerque (2009), os ambientes empresariais são caracterizados por constantes transformações, que são profundas e decorrem de aspectos tecnológicos, mercado global e a competitividade dentro e fora do país. Nesse contexto, é possível entender a diversidade da força de trabalho que, somada a esses fatores, impacta nos ambientes organizacionais. O planejamento deve prever políticas de gestão de pessoas alinhadas a esses cenários internos de mudanças rápidas, com a finalidade de intensificar a produtividade, aumento de receita, bem como a redução de gastos e geração de valor, convertendo estratégia em ações.

Resumindo as visões dos autores como Marras (2002), Eboli (2002), Balducci e Kanaane (2007), Hanashiro, Teixeira e Zacarelli (2008), o alinhamento da gestão estratégica de pessoas aos objetivos organizacionais requer um conjunto planejado de políticas e/ou práticas de gestão de pessoas que contemplem, desde os processos de contratação, retenção e desenvolvimento de pessoas, às grandes transformações dos ambientes organizacionais que decorrem das inovações, tecnologias, sustentabilidade e demais variáveis externas que permeiam o mundo contemporâneo dos negócios. A esses processos, observam-se as práticas de gestão de pessoas que contemplem processos seletivos criteriosos para a busca de talentos, planos de desenvolvimento das competências humanas, remuneração e o desenvolvimento das lideranças para o trabalho coletivo.

REAd | Porto Alegre - Edição 78 - Nº 2 - maio/agosto 2014 - p. 371-396 
Paschoal Palombino Primo, Eduardo de Camargo Oliva \& Edson Keyso de Miranda Kubo

Para Lacombe (2006), é na essência das políticas e práticas de Gestão de Pessoas que o comportamento se torna o principal intermediário entre a estratégia e a sua efetiva implementação, devendo ser orientado pelas práticas de Recursos Humanos e que, portanto, as práticas adotadas devem promover comportamentos consistentes com a estratégia.

Mediante estudos de Lacombe e Chu (2008), grande parte da pesquisa acadêmica sobre a Gestão de Pessoas adota a abordagem estratégica de Recursos Humanos, assumindo ser possível, por meio de políticas e práticas, identificar e desenvolver comportamentos necessários à implantação da estratégia organizacional.

Para Boxall e Purcell (2007), a gestão estratégica de pessoas é um processo complexo que está em constante evolução e em discussão no meio acadêmico. Sua definição e as relações com outros aspectos do planejamento e estratégia empresarial não são absolutas e parecem variar entre escritores. Neste sentido, Combs, Liu, Hall e Ketchen (2006), esclarecem que práticas de gestão de pessoas diferenciadas contribuem para o desempenho das organizações, em especial, quando direcionadas para o desenvolvimento das competências dos colaboradores (MUELLER, 1996), assim como autonomia de trabalho e oportunidade de crescimento profissional.

No entanto, a estratégia pode ser considerada como uma abordagem geral para a gestão estratégica de Recursos humanos, de acordo com as intenções da organização sobre o rumo que pretende tomar. Sob a Gestão de Pessoas, alinhar estrategicamente os interesses individuais e grupais aos objetivos da organização supostamente tem sido o maior desafio das organizações para que seus objetivos sejam atingidos.

\section{GESTÃO DE PESSOAS EM INSTITUIÇÕES DE ENSINO SUPERIOR}

Estudos realizados por Freitas (2010), sobre gestão de pessoas na Universidade de São Paulo (USP), Universidade de Campinas (UNICAMP) e Universidade Estadual Paulista (UNESP) revelam que elas estão desenvolvendo ou procurando desenvolver práticas de gestão de pessoas de acordo com os atuais desafios enfrentados pelas organizações. O autor tomou por base comparativa de análise os princípios da Administração Pública, tendo o estudo demonstrado que as universidades pesquisadas praticam uma gestão de pessoas semelhante às aplicadas nas organizações privadas, como programas de socialização, programas de desenvolvimento profissional e premiação atrelada aos resultados. As 
Gestão estratégica de pessoas para pesquisadores em administração nas universidades privadas

universidades estão sendo ágeis buscando integrar as pessoas aos objetivos organizacionais, mesmo diante do aspecto moroso da legislação que rege a gestão de pessoas.

Já os estudos feitos por Kiste (2001) sobre as políticas e práticas de gestão de pessoas aplicadas aos funcionários técnico-administrativos de universidades privadas na cidade de São Paulo, constatou que as organizações estudadas não estão “preparadas”, sob a ótica de gestão de pessoas, para serem organizações prestadoras de serviços que satisfaçam as exigências dos seus clientes. Segundo Kiste (2001), embora elas se sustentem, ao longo dos anos, por suas filosofias de administração baseadas em suas tradições no ramo educacional, levanta-se a hipótese, quanto à capacidade de geração de resultados que essas filosofias de administração terão frente aos novos e futuros cenários organizacionais. De acordo com as análises dos estudos feitos pelos autores supracitados, percebe-se uma divergência entre os estilos de gestão de pessoas para universidades públicas e universidades privadas, constatando-se que as práticas de gestão de pessoas nas universidades privadas não estão alinhadas aos seus planos globais de desempenho (KISTE, 2001).

Para Freitas (2010), essas instituições procuram atender às exigências do Plano de Desenvolvimento Institucional (PDI) apresentado ao Ministério da Educação (MEC) que estabelece as diretrizes quanto à filosofia de trabalho das IES, à missão a que se propõem, às diretrizes pedagógicas que orientam suas ações, a sua estrutura organizacional e às atividades acadêmicas que desenvolvem e/ou que pretendem desenvolver, mas pouco evoluíram na gestão estratégica de pessoas para os docentes. O PDI, exigido pelo Ministério da Educação, impõe às universidades a obrigação de criarem, em seus modelos de gestão, ações que possibilitem o desenvolvimento e a capacitação docente. De acordo com Toh, Morgeson, Campion (2008), na valorização do fator humano pelas organizações, as pessoas passam a orientar-se para a organização, estando mais comprometidas com um relacionamento de maior duração, através de desenvolvimento profissional e da carreira. Assim as organizações precisam implementar políticas e/ou práticas de gestão de pessoas que sejam capazes de recompensar os esforços dos colaboradores e valorizar seus conhecimentos e competências, por meio de incentivos e recompensas justas e equitativas.

\section{PÓS-GRADUAÇÃO NO BRASIL}


Paschoal Palombino Primo, Eduardo de Camargo Oliva \& Edson Keyso de Miranda Kubo

Segundo Velloso (2004), a Pós-Graduação no Brasil tem passado por notável expansão, além de ampliar muito sua abrangência quanto a áreas do conhecimento. A Pós-Graduação, instituída formalmente em meados dos anos 60, e conforme dados encontrados em Martins (2003), no início dos anos 90, já ascendia a quase 1.500 cursos Stricto Sensu, abrangendo todas as áreas do conhecimento. Em anos mais recentes, observou-se uma ampliação dos cursos e matrículas. Em 2003, havia mais de 2.600 cursos de pós-graduação Stricto Sensu no país, em cerca de 1.800 programas, formando 23 mil mestres e 8 mil doutores no ano, com um contingente de estudantes que alcançava a casa dos 110 mil (VELLOSO, 2004).

Nesse sentido, dados da Coordenação de Aperfeiçoamento de Pessoal de Nível Superior (CAPES), agência vinculada ao Ministério da Educação, confirmam essa tendência crescente da Pós-Graduação no país, conforme a figura 1.

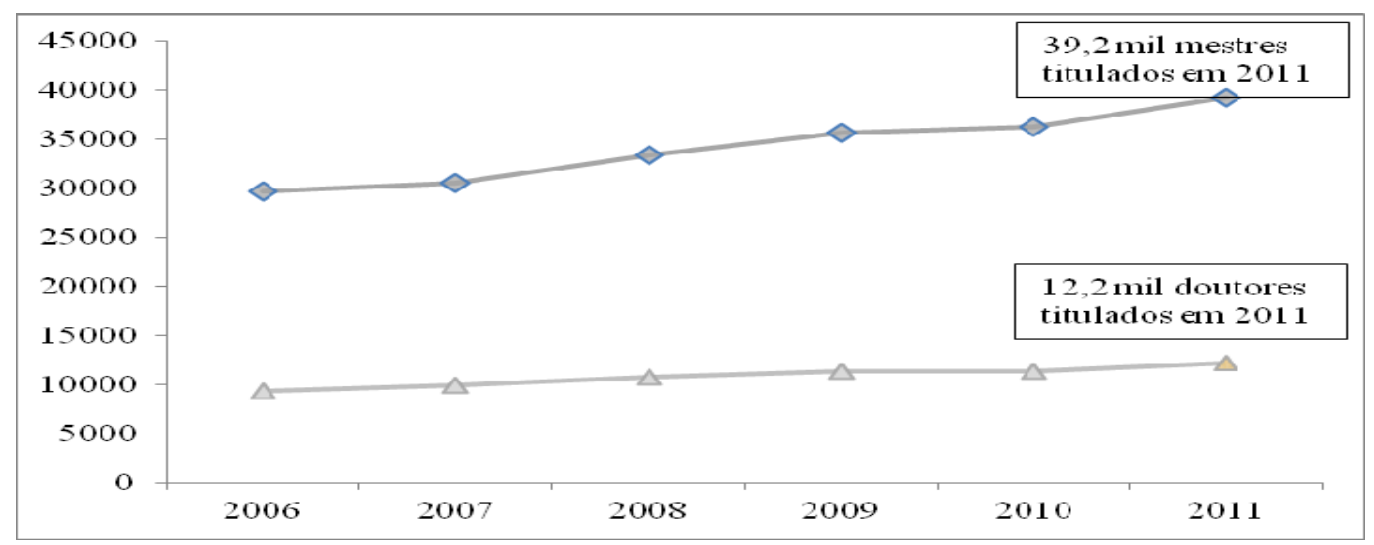

Figura 1 - Evolução de Titulação de Mestres e Doutores no Brasil Fonte: Geocapes, 2012)

Segundo dados da Capes, o número de mestres e doutores titulados no Brasil, no período de 2006 a 2011, passou de 38 mil para cerca de 52 mil. Ainda de acordo com o órgão, em 2011, 12 mil receberam o título de doutor e 39 mil o de mestre. Outro dado relevante que sugere a evolução da Pós-Graduação no Brasil é o crescimento da quantidade de estudantes bolsistas, mestres e doutores. Em 2006, foram 31658 e em 2011 foram 67162 alunos agraciados por bolsas de estudos no Brasil (CAPES, 2011).

\section{PROCEDIMENTOS METODOLÓGICOS}

O objetivo principal desta pesquisa foi descrever e analisar as políticas e/ou práticas de Gestão de Pessoas das Instituições Privadas de Ensino Superior da região metropolitana da REAd | Porto Alegre - Edição 78 - Nº 2 - maio/agosto 2014 - p. 371-396 
Gestão estratégica de pessoas para pesquisadores em administração nas universidades privadas

Grande São Paulo, aplicadas aos docentes pesquisadores dos cursos de Administração Stricto Sensu. Foram pesquisadas 8 (oito) Universidades. A escolha dessas instituições se deve ao fato desta região concentrar um grande número delas que disponibilizam cursos para mestrado e doutorado em Administração, contribuindo para a formação de novos pesquisadores e o desenvolvimento e fomento à pesquisa científica. A escolha do curso de administração se deve por ser esse um dos mais representativos em termos de procura na formação de mestres e doutores nas áreas de Ciências Sociais Aplicadas.

Entre as universidades selecionadas para o estudo, quatro delas também possuem o doutorado em Administração. Portanto, os autores não trabalharam com amostra, caracterizando-se esta pesquisa como um censo, pois acessou toda população.

Tabela 1 - Dados demográficos das IES pesquisadas

\begin{tabular}{lc}
\hline Dados & Total de IES pesquisadas (8) \\
\hline Números de cursos de pós-graduação & 4 \\
Mestrado & 4 \\
Mestrado e Doutorado & \\
& 3 \\
Número de docentes pesquisadores permanente & 3 \\
Abaixo de 15 & 2 \\
Entre 15 e 30 & 3 \\
Acima de 30 & \\
\hline
\end{tabular}

Fonte: Dados dos autores

A tabela 1 demonstra que são poucas as instituições com menos de 15 docentes no quadro permanente, e isso pode sinalizar que os programas estão se preparando para obter uma melhor classificação no seu conceito da CAPES.

Observa-se que os gestores de cursos estão vinculados aos programas de Administração Stricto Sensu em média há três anos e nove meses, sendo que apenas um gestor está no programa há um ano e meio. Os gestores de Recursos Humanos estão em média há nove anos e meio em seus cargos, e o tempo mínimo observado é de três anos.

Dos dezoitos docentes pesquisadores que participaram da pesquisa, apenas um docente tem tempo inferior a 2 anos de vínculo no programa. Em média os docentes atuam há cinco anos e oito meses no Stricto Sensu em Administração. Estabeleceu-se como objetivo entrevistar pessoas que estivessem atuando pelo menos há dois anos em seus respectivos REAd | Porto Alegre - Edição 78 - Nº 2 - maio/agosto 2014 - p. 371-396 
Paschoal Palombino Primo, Eduardo de Camargo Oliva \& Edson Keyso de Miranda Kubo cargos, como tempo mínimo imaginável para conhecimento das políticas e práticas de gestão de pessoas existentes nas instituições pesquisadas, e assim, poder balizar melhor suas opiniões sobre elas. Os dois participantes da pesquisa com tempo inferior á dois anos na função representam apenas $6,6 \%$ do total de entrevistados.

O estudo é exploratório e qualitativo, cuja finalidade foi de proporcionar uma visão ampla sobre as políticas e/ou práticas de gestão de pessoas, das instituições de ensino superior privadas da região metropolitana da grande São Paulo, para os pesquisadores dos cursos de Administração Stricto Sensu. Esse tipo de pesquisa sugere constituir a primeira etapa de uma investigação que poderá se ampliar e que outros tipos de pesquisas podem ser utilizados para aprofundar os resultados alcançados por esta pesquisa (GIL, 2010).

A pesquisa é considerada de fonte primária, pois teve os dados obtidos por meio de contatos diretos dos autores com a situação pesquisada, com a finalidade de compreender os fenômenos segundo a visão dos agentes sociais da pesquisa. Para Creswell (2007), a pesquisa qualitativa é interpretativa e o pesquisador faz a interpretação dos dados.

Os dados foram coletados por meio de entrevistas semiestruturadas com os gestores de programas de pós-graduação, gestores de RH e com os docentes pesquisadores, todos vinculados às universidades pesquisadas. Foram pesquisados os sites e documentos, principalmente os acordos coletivos das instituições. As entrevistas seguiram um roteiro predefinido levando em conta os referenciais teóricos utilizados na pesquisa. Aos gestores de programas, pediu-se que opinassem sobre as estratégias de pessoal que são deliberadas para a gestão dos docentes que atuam nos programas de pós-graduação Stricto Sensu em Administração e como são aplicadas as políticas e/ou práticas de Gestão de Pessoas, as estratégias de estímulo para o engajamento e comprometimento do pesquisador com a universidade e estratégias de desenvolvimento das competências do docente em relação aos programas de pós-graduação.

Aos gestores da área de Recursos Humanos, pediu-se que opinassem sobre as políticas e/ou práticas de gestão de pessoas utilizadas pela universidade para a Contratação, Retenção e Desenvolvimento, as formas de comunicação das práticas de gestão de pessoas entre a instituição e os docentes pesquisadores e o compartilhamento da função de gestão de RH com os gestores de programas. Aos pesquisadores, pediu-se que opinassem sobre seus conhecimentos sobre as políticas e/ou práticas de gestão de pessoas existentes na universidade, como são avaliados pelos seus resultados, se o sistema de remuneração está ou não vinculado ao cumprimento de metas, planos de benefícios, práticas de desenvolvimento REAd | Porto Alegre - Edição 78 - Nº 2 - maio/agosto 2014 - p. 371-396 
Gestão estratégica de pessoas para pesquisadores em administração nas universidades privadas

das competências e carreiras, planos de incentivo à pesquisa acadêmica, infraestrutura de trabalho e tecnologia, práticas de valorização e comprometimento do pesquisador com a instituição. As entrevistas foram gravadas e transcritas para análise posterior. Foram entrevistadas 30 pessoas, sendo 8 (oito) gestores de programas, 4 (quatro) gestores de RH e 18 (dezoito) pesquisadores, em 8 (oito) universidades privadas da região metropolitana da grande São Paulo.

Na tabulação dos dados utilizou-se a técnica de Análise de Conteúdo em que, na fase inicial, procedeu-se a análise semântica do vocabulário usado nas entrevistas e posteriormente a análise em si dos conteúdos transcritos, na qual se identificou as ideias e opiniões manifestadas pelos atores da pesquisa durante a entrevista.

A análise de dados qualitativos (GIBBS, 2009) é essencialmente significativa e demonstra grande diversidade. A análise de dados qualitativos não inclui contagens e medidas, pois reflete essencialmente a comunicação humana em suas formas escrita, auditiva ou visual; por comportamento, simbolismos ou artefatos culturais. Para auxiliar a análise do conteúdo das entrevistas e devido ao volume de conteúdo das transcrições, foi utilizado o software Atlas Ti 6.2.27. Após a transcrição das entrevistas, foram realizados os processos de codificação, microanálise dos dados e identificação e validação da categoria.

Conforme Godoi, Bandeira-de-Mello e Silva (2006), a codificação é um processo que conduz o pesquisador do nível de abstração dos dados específicos para o nível do conceito. Os códigos criados foram agrupados em torno do tema Gestão de Pessoas que se tornou a categoria única e principal. Assim a categoria é constituída de códigos abstratos sem conexão direta com os dados. Para validação da categoria, procedeu-se a verificação do nível de ocorrência dos códigos. A análise de conteúdo envolveu 30 participantes e foi realizada, separadamente, por níveis de participantes, sendo eles representados pelas letras: (GP) para Gestores de Programas, (GRH) para Gestores de Recursos Humanos e (P) para Pesquisadores.

Os Gestores de Programas e Gestores de Recursos Humanos, em suas citações e pela natureza de suas funções representam as instituições pesquisadas quando opinam sobre as políticas e/ou práticas de gestão de pessoas. Os docentes pesquisadores são os protagonistas da pesquisa por serem eles o objetivo central da mesma. Optou-se neste artigo em apresentar e enfatizar a percepção totalizante em torno da categoria principal (Gestão de Pessoas) na apresentação dos resultados, sem segmentar as percepções pelos grupos de participantes da pesquisa. Quando pertinente, exemplos de falas representativas no texto são ressaltadas e aí 
Paschoal Palombino Primo, Eduardo de Camargo Oliva \& Edson Keyso de Miranda Kubo ocorre a identificação das citações. A próxima subseção descreverá o processo de codificação e categorização dos dados.

\subsection{Codificação e categorização dos dados}

Para identificação, registro das partes das citações dos autores e classificação que, em algum sentido exemplificam a mesma ideia teórica e descritiva, criaram-se códigos com a finalidade de indexar ou categorizar os textos transcritos (GIBBS, 2009). Neste sentido, foram criados os seguintes códigos: a) Políticas e/ou práticas de gestão participativa, b) Indicadores de Resultados, c) Suporte à pesquisa, d) Destaques em gestão de pessoas, e) Políticas e/ou práticas de gestão de pessoas declaradas e f) Políticas e/ou práticas de retenção. Para cada um desses códigos e com o auxílio do Atlas TI, organizou-se os trechos comuns e extraídos das falas dos entrevistados que melhor expressassem as citações em torno do código atribuído.

Assim, decorridos o processo de codificação, passou-se à formação da categoria gestão de pessoas conforme demonstra a figura 2.

\begin{tabular}{|l|}
\hline \multicolumn{1}{c|}{ Pilares da GP } \\
\hline Recrutamento e Seleção de Pessoal \\
\hline Aperfeiçoamento e Desenvolvimento de Pessoal \\
\hline Compensação e Benefícios \\
\hline Relações com Funcionários e QVT \\
\hline Estratégias Organizacionais em GP \\
\hline
\end{tabular}

Figura 2 - Codificação e Categorização da Gestão de Pessoas Fonte: dados da pesquisa (2012)

Para a construção da categoria gestão de pessoas, foram analisados os conteúdos descritos em cada código conforme acima mencionado e criados 5 (cinco) processos representativos da gestão de pessoas, assim denominados pilares da gestão de pessoas que passam agora a compor a categoria de Gestão de Pessoas. Dito isso, passa-se a descrever cada um desses processos da Gestão de Pessoas. 1) Recrutamento e Seleção de Pessoal. Neste processo foram registrados e selecionados os critérios utilizados pelas universidades pesquisadas para o recrutamento e seleção dos pesquisadores. 2) Aperfeiçoamento e Desenvolvimento de Pessoal. Neste processo foram registradas e relacionadas às estratégias REAd | Porto Alegre - Edição 78 - Nº 2 - maio/agosto 2014 - p. 371-396 
Gestão estratégica de pessoas para pesquisadores em administração nas universidades privadas

utilizadas pelas IES pesquisadas para o desenvolvimento das competências dos docentes pesquisadores. Incluem-se nesta seção, práticas de valorização para o fortalecimento do desempenho individual e de grupo, os investimentos em cursos, participação em eventos e outras atividades que possam contribuir para o aprimoramento competitivo das pessoas e das instituições. 3) Compensação e Benefícios. Neste processo foram registradas as citações dos entrevistados e relacionadas com as estratégias utilizadas pelas IES pesquisadas para a remuneração total dos docentes pesquisadores. Incluem-se os critérios de premiação, planos de assistência médica e outros benefícios efetivos da gestão de pessoas. 4) Relações com funcionários e Qualidade de Vida. Neste processo foram registradas as citações dos entrevistados e relacionadas com as estratégias utilizadas pelas IES. 5) Estratégias Organizacionais em GP. Neste processo foram registradas as práticas de gestão de pessoas e as estratégias utilizadas pelas IES pesquisadas para o cumprimento de metas e objetivos relacionados aos programas de pós graduação em Administração Stricto Sensu.

\section{ANÁLISE E INTERPRETAÇÃO DOS RESULTADOS DA PESQUISA}

Decorridos o processo de codificação e categorização dos dados da pesquisa (Figura 2), demonstram-se a seguir, as análises das políticas e/ou práticas de gestão de pessoas identificadas nos estudos e comparadas à luz da literatura.

\subsection{Recrutamento e seleção de pessoal}

Do processo de análise, houve evidências das seguintes práticas de gestão de pessoas para o processo de recrutamento e seleção de pessoal para os docentes pesquisadores. 1) As IES formalizam o processo de recrutamento e seleção dos professores da Pós-Graduação por meio de editais e com base em regimento interno. 2) O Processo seletivo dos candidatos é feito pelo critério de análise de currículo (titulação), publicações e banca avaliadora com professores internos e externos. 3) Observou-se em um determinado caso a contratação por convite, sem que ocorressem as formalidades habituais e legais do processo de seleção. A recomendação da contratação cabe ao gestor do programa, e a aprovação à Pró-reitoria ou até mesmo a Reitoria em determinados casos. Não obstante a existência de procedimentos formais para a contratação de pessoas, a aparente preocupação dos gestores em identificar e 
Paschoal Palombino Primo, Eduardo de Camargo Oliva \& Edson Keyso de Miranda Kubo contratar os melhores pesquisadores do mercado para seus programas conduz a uma ação muito pessoal, e não recebe a devida atenção da área de gestão de recursos humanos, que deveria se envolver mais no processo seletivo. Presume-se que não o façam por falta de uma política de atratividade clara e objetiva por parte das instituições, que seja elaborada com base em visão estratégica de mercado e que contenha diretrizes para o processo de recrutamento e seleção de pessoal. Para Hanashiro, Teixeira e Zacarelli (2008), a escolha do melhor candidato deve atender às necessidades técnicas da função, mas torna-se importante o alinhamento das competências do candidato com as competências da organização. Investir no processo de busca de talentos pode proporcionar às organizações o diferencial competitivo para a manutenção e continuidade do sucesso, no caso o educacional (MONTEIRO, 2010).

\subsection{Aperfeiçoamento e desenvolvimento de pessoal}

Do processo de análise, evidenciaram-se práticas de gestão de pessoas para o processo de aperfeiçoamento e desenvolvimento de pessoal para os docentes pesquisadores. Na maioria dos casos analisados, observou-se a existência de plano de carreira para os docentes pesquisadores, conforme citado por um dos entrevistados: “A Instituição tem uma política única e que é bem interessante, assim, todos os professores têm esse mesmo plano de carreira, tanto horistas como professores em tempo integral” (GP4).

Algumas instituições pesquisadas oferecem cursos internos ou externos para o desenvolvimento das competências dos docentes pesquisadores, mas em grande parte atendem apenas aos níveis administrativos, como os treinamentos em informática (planilhas eletrônicas, pacote office, segurança, entre outros).

Há suporte financeiro para a participação do docente pesquisador em eventos acadêmicos nacionais e internacionais, porém a prioridade seria os projetos aprovados pelas agências de fomento à pesquisa.

Para GRH4, a política de desenvolvimento de pessoal do Stricto Sensu está no suporte financeiro dado ao docente pesquisador para atender suas demandas de pesquisa:

Como política de desenvolvimento, nós temos uma verba e essa verba ela é distribuída de acordo com a demanda das áreas envolvidas. Então, normalmente a primeira tentativa que se faz é a liberação pela CAPES, que é o órgão que mais financia . Mas não necessariamente. Qualquer um dos órgãos de fomento. A primeira situação é, quando não há disponibilidade, é feito a análise para liberação com recursos próprios da instituição. (GRH4)

REAd | Porto Alegre - Edição 78 - Nº 2 - maio/agosto 2014 - p. 371-396 
Gestão estratégica de pessoas para pesquisadores em administração nas universidades privadas

Evidenciou-se, em alguns casos, a prática da avaliação de desempenho da produção acadêmica do professor para a evolução na carreira. Capacitar pessoas para um melhor desempenho profissional tem sido o caminho mais lógico e racional para a formação de times de trabalho. A ordem mundial requer mudanças e aprimoramento constante das pessoas na busca do conhecimento em todos os sentidos. Nas instituições de ensino superior não é diferente, a geração e a disseminação do conhecimento se constituem na principal razão da existência das universidades e como tal, supõe-se merecer total atenção por parte da direção das IES. Para Eboli (2002), o setor de treinamento e desenvolvimento de pessoas vem adquirindo relevância no contexto da gestão de pessoas, momento em que a educação continuada para o trabalho recebe maior importância, o que justifica a tendência da criação das universidades corporativas como fator estratégico na formação e desenvolvimento de pessoas no mundo corporativo organizacional. No entanto, os resultados da pesquisa neste processo revelam poucas ações que valorizem e propiciem o desenvolvimento das competências dos docentes pesquisadores, oportunizando verbas para a pesquisa científica e participação em eventos, planos de carreira, constituindo assim em ações isoladas dos programas de Pós-Graduação, pois não integram um plano estratégico corporativo. A ausência da área de gestão de pessoas é notada nestes processos, demonstrando uma prática mais passiva, quando não é percebido o envolvimento desses profissionais em atividades conjuntas para levantamento de necessidades de treinamento e formulações de programas de desenvolvimento que possam contribuir para a capacitação dos docentes pesquisadores.

Observa-se que os profissionais de gestão de pessoas necessitam atuar ao mesmo tempo, no estratégico e no operacional, concentrando-se em atividades que requerem a visão integrada das organizações, no longo e no curto prazo, podendo assim exercer múltiplos papéis conforme afirma Ulrich (1998).

Outro ponto a ser considerado é a pouca frequência de práticas de avaliação de desempenho. Os gestores de programas avaliam seus professores, tendo como métrica suas performances produtivas e comparadas aos níveis de exigência da CAPES, ou em metas propostas por eles. No entanto, o processo de avaliação deve prever outros fatores que não os exclusivos de natureza produtiva, mas, complementar com ações que envolvam aspectos comportamentais, tais como relacionamento, trabalhos em equipe, criatividade e inovação, liderança, negociação; fatores estes, presentes nos ambientes de trabalho contemporâneos. Portanto, não se verificou a premissa teórica da gestão de pessoas, quando são formuladas 
Paschoal Palombino Primo, Eduardo de Camargo Oliva \& Edson Keyso de Miranda Kubo avaliações formais, que assegurem medir desafios previamente planejados com enfoque estratégico para os resultados e das vantagens competitivas criadas pelas pessoas e organizações (BARRETO; COSTA, 2010).

\subsection{Compensação e Benefícios}

Para este item e na maioria dos casos analisados, constatou-se nas instituições pesquisadas a existência de tabelas salariais com valores fixos para a remuneração do pesquisador, sendo estes, estabelecidos com base em referenciais de mercado.

Outra constatação é a remuneração do pesquisador não estar vinculada à sua produtividade, exceto em um caso em que foi verificada a existência de pagamento de um prêmio por atingimento de metas e objetivos. A pesquisa revelou a existência de planos de benefícios e que são comuns para todos que integram o quadro permanente das instituições. Dentre os benefícios pode-se destacar a assistência médica, seguro saúde e bolsa de estudos para filhos de funcionários. Portanto são benefícios corporativos e não exclusivos dos pesquisadores. Para Marras (2002), uma gestão estratégica de pessoas responde por programas que desenvolvem a capacidade humana e organizacional, o enfrentamento e aplicação de mudanças, a manutenção e o estímulo à motivação no trabalho e a qualidade total na organização. Uma dessas mudanças é o sistema de remuneração. Enquanto a Administração de Recursos Humanos tradicional desenvolve planos de estruturas salariais focadas nas exigências do cargo, a gestão estratégica de gestão de pessoas busca ampliar esse sistema com o que se denomina remuneração estratégica. A remuneração estratégica, na definição de Marras (2002) representa um modelo que permite premiar funcionários que se destacaram em seus desempenhos em um determinado período em suas organizações. Dessa afirmação, infere-se que o modelo de remuneração estratégica faz com que os funcionários passem a ser considerados em consonância com um conjunto de fatores que possuem e influenciam diretamente nos resultados que possam oferecer às organizações.

Como resultado das análises neste processo, observa-se que as IES pesquisadas não praticam a remuneração estratégica, mas balizam suas práticas na remuneração fixa e com foco nos níveis de exigências da função. Para Oliva e Albuquerque (2006), a remuneração por resultados representa um sistema de bônus voltado às equipes e às pessoas. Outro ponto que chama a atenção é que as IES não possuem um programa de benefícios diferenciados para os docentes pesquisadores. A prática de benefícios, sobretudo pela relevância das atividades dos REAd | Porto Alegre - Edição 78 - Nº 2 - maio/agosto 2014 - p. 371-396 
Gestão estratégica de pessoas para pesquisadores em administração nas universidades privadas

professores pesquisadores, poderia ser considerada antagônica às praticas de mercado quando são percebidos planos de benefícios diferenciados para executivos em relação aos demais níveis da organização. Integrar planos de benefícios ao sistema de remuneração tem sido uma prática criativa das organizações que buscam práticas inovadoras de gestão de pessoas.

\subsection{Relações com funcionários e qualidade de vida no trabalho}

Neste item há reuniões programadas entre gestores de programas e suas equipes, como canal de comunicação para tratar dos assuntos acadêmicos do programa. A comunicação entre a área de $\mathrm{RH}$ e os Pesquisadores é feita por um portal de $\mathrm{RH}$ existente na página das instituições pesquisadas e através de e-mails e mailing. Verificou-se a prática de confraternização de final de ano, comemoração de aniversário de colegas de trabalho, sendo esta prática atribuída às iniciativas do próprio grupo. Foram observadas nas análises, citações por parte dos pesquisadores sobre a existência de um clima harmonioso de trabalho, como forma de estimular as boas práticas de relacionamento intergrupal. Em apenas uma IES pesquisada, observou-se a comemoração do Dia do Professor, incluindo-se os professores da Pós-Graduação (prática corporativa da IES). No que se refere às políticas e/ou práticas de envolvimento, o processo de comunicação das IES pesquisadas está no poder dos gestores em organizar reuniões programadas com suas equipes de professores para informar, deliberar, cobrar resultados e promover a sinergia necessária para integração do time de trabalho. Esse modelo de comunicação é entendido como sistema de comunicação regulador, na medida em que são expostas as ordens, regras e instruções reguladoras dos processamentos que ocorrem na organização (TONET; PAZ, 2006). Nesta mesma direção, os canais de comunicação (online) da área de Recursos Humanos com os docentes pesquisadores, configuram-se numa comunicação operacional onde são transmitidas informações dos processos da área e informes de documentos legais da administração de pessoal. Ainda segundo os autores, o compartilhamento de conhecimentos no trabalho e focado nos grupos de trabalho, considera ainda o sistema de feedback como canais de comunicação dentro da organização para o retorno das informações, sendo esta prática pouco observada pela área de gestão de pessoas.

No que tange à gestão da qualidade de vida no trabalho, Nascimento e Pessoa (2007) analisaram o emprego do lazer como fator de aprimoramento dos programas de qualidade de vida no trabalho. Os autores concluíram em seus estudos que o lazer nas organizações é capaz 
Paschoal Palombino Primo, Eduardo de Camargo Oliva \& Edson Keyso de Miranda Kubo de contribuir significativamente para a qualidade de vida do indivíduo no trabalho, além de beneficiar diretamente a própria organização e, ainda, que tal abordagem reflete ações efetivas de responsabilidade social empresarial. Incluem-se nesta análise as práticas de entretenimento e de eventos comemorativos verificados entre os docentes dos programas de Pós-Graduação Stricto Sensu em Administração das instituições pesquisadas, como atos isolados e alheios às ações efetivas de bem estar social, mas que geram satisfação entre eles. Por outro lado, a “Administração da Contribuição dos Funcionários” mencionada nos estudos de Ulrich (1998), reforça que o profissional de gestão de pessoas, no papel de defensor, deve estar atento às necessidades dos funcionários, ouvindo-os e buscando formas para atendê-los, com vistas à melhor contribuição destes para o alcance dos objetivos estabelecidos pela organização.

\subsection{Estratégias organizacionais em Gestão de Pessoas}

A busca pela elevação do status classificatório de seus respectivos programas junto a CAPES tem incentivado as IES na implementação de estratégias organizacionais específicas. Para alguns casos, observou-se a inserção do professor de graduação como uma espécie de parceiro dos professores dos programas de Pós-Graduação, na tentativa de aumentar a produtividade dos programas em termos de produção científica. Observou-se nas IES a prática da marcação do ponto pelos professores dos programas e na maioria dos casos, a exigência da permanência do professor no local de trabalho. As IES, em sua maioria, oferecem infraestrutura física e base de dados para o desenvolvimento do trabalho dos professores dos programas (Salas individuais, portais de consulta para acesso à periódicos, bibliotecas, TI e outros meios de comunicação). De um modo geral, as IES pesquisadas definem suas estratégias focadas no cumprimento de metas e objetivos que se pretendem atingir nos programas de Pós-Graduação Stricto Sensu em Administração. Por outro lado, para os docentes pesquisadores, a gestão de pessoas segue, em sua maioria, procedimentos operacionais que são oriundos da área de Administração de Pessoal, tais como a marcação de ponto dos professores, controle de frequência, informações sobre os benefícios comuns, férias, e outros fatores legais, previstos em Convenção Coletiva de Trabalho, Regimento interno e Consolidação das Leis Trabalhistas (CLT). Isso pôde ser constatado pela fala de um dos atores da pesquisa: “O RH é ultrapassado, pois fica controlando apenas o ponto dos professores” (P11).

Não foram observadas práticas estratégicas de gestão de pessoas nas IES investigadas. REAd | Porto Alegre - Edição 78 - Nº 2 - maio/agosto 2014 - p. 371-396 
Gestão estratégica de pessoas para pesquisadores em administração nas universidades privadas

Para Ulrich (1998), o RH deve atuar como parceiro estratégico no processo de melhoria contínua da organização, em que se verifica o foco da atuação estratégica da área em consonância às estratégias da organização, podendo assim contribuir para a consecução de objetivos e resultados esperados. Neste sentido, observa-se que as IES não parecem possuir estratégias de gestão de pessoas que valorizem os pesquisadores ou recompensem seus esforços individuais ou da equipe como forma de retribuição de seus conhecimentos e competências. Considerando os múltiplos papéis exercidos pelo profissional de $\mathrm{RH}$ (ULRICH, 1998), é oportuno citar as práticas de gestão de pessoas para a manutenção de um clima de trabalho harmonioso e produtivo, que deve encorajar os funcionários a assumirem novas abordagens de mudança. Para Balducci e Kanaane (2007), as lideranças exercem papel de fundamental importância para haver o alinhamento entre necessidades humanas e organizacionais, e o fortalecimento de valores culturais que permeiam os ambientes de trabalho organizacionais.

\section{CONSIDERAÇÕES FINAIS}

As políticas e/ou práticas de gestão de pessoas para os docentes pesquisadores das IES pesquisadas não parecem contemplar planos que sinalizem a existência de uma gestão estratégica de pessoas. As ações estratégicas deliberadas para os programas de Pós-Graduação Stricto Sensu em Administração das IES pesquisadas seguem objetivos oriundos do ambiente externo, e não foi observada formalmente a existência de um planejamento estratégico de gestão de pessoas e que considerasse o pesquisador como elemento central para o cumprimento de resultados. Outro ponto a destacar é que a área de Gestão de Pessoas das instituições pesquisadas tem atuação focada nos processos de RH e, na maioria das ações, busca atender às obrigações legais que regem as relações de trabalho entre os professores dos programas de Pós-Graduação e suas instituições.

Pelas análises feitas, depreendeu-se que as políticas e/ou práticas de gestão de pessoas das IES atendem melhor a outros níveis de ocupações que atuam nas áreas técnicas e administrativas do que para os docentes pesquisadores. No que tange aos benefícios sociais, os docentes pesquisadores pouco valorizam essas práticas, pois elas são corporativas das instituições e não atendem aos seus níveis de expectativas, em especial os planos médicos que são oferecidos na modalidade básica. Os Pesquisadores, no geral possuem seus planos 
Paschoal Palombino Primo, Eduardo de Camargo Oliva \& Edson Keyso de Miranda Kubo médicos por recursos próprios e fora da rede credenciada oferecida pelas instituições que trabalham.

As instituições de ensino superior, ainda que com suas peculiaridades, inserem-se em um mercado educacional competitivo e por isso estão sujeitas às regras que ditam esse mercado. Portanto essas IES são pressionadas a empreenderem uma gestão moderna e estratégica de gestão de pessoas.

Nesta pesquisa, observou-se que os Programas de Pós-Graduação em Administração das oito universidades privadas possuem em geral políticas e práticas que ainda permanecem distantes da Gestão Estratégica de Pessoas, embora se empenhem na formação de novos professores e pesquisadores.

Os docentes pesquisadores afirmam não conhecerem a existência de políticas e/ou práticas de gestão de pessoas nas instituições, mas destacam alguns fatores considerados relevantes tais como a existência de planos de carreira, reconhecidos por alguns como importantes para sua evolução profissional. Há também recursos financeiros destinados às atividades de pesquisa, mas com ressalvas de alguns professores que alegam serem insuficientes para o cumprimento de seus objetivos; existe infraestrutura como salas individuais de trabalho, laboratórios de informática, bibliotecas, base de dados para consultas acadêmicas, ambiente de trabalho estimulante para a formação de times de trabalho, reuniões de planejamento para feedback de produções científicas, participação em eventos internos e externos destinados à ampliação do conhecimento científico.

Por outro lado, levando-se em conta as opiniões dos gestores de programa e gestores de RH, que são considerados neste artigo como os representantes pela implementação, gerenciamento e manutenção das práticas de gestão de pessoas nas IES, os resultados indicam que as práticas de gestão de pessoas corporativas das IES são pouco significativas para os docentes pesquisadores, mas representativas para os demais níveis ocupacionais das instituições, por atenderem às necessidades mais primárias dos seres humanos.

Dentre essas práticas tidas como primárias, encontram-se os planos médicos, bolsa de estudos, seguro de vida, e outros benefícios previstos em convenção coletiva de trabalho ou em regimentos internos das instituições.

No entanto, os resultados não representaram uma surpresa, uma vez que os autores tinham uma ideia inicial de que as práticas de gestão de pessoas do segmento da Educação Superior Brasileira tendem a não seguir os modelos praticados pelo mercado corporativo.

REAd | Porto Alegre - Edição 78 - Nº 2 - maio/agosto 2014 - p. 371-396 
Gestão estratégica de pessoas para pesquisadores em administração nas universidades privadas

Os dirigentes, entre eles reitores, pró-reitores, diretores de áreas e gestores de curso e gestores de pessoas, representam a base de sustentação da instituição, por isso, precisam construir/orientar as políticas de gestão de pessoas garantindo aos pesquisadores o contínuo desenvolvimento profissional e pessoal, para que todos na instituição estejam engajados, comprometidos, motivados e preparados para o desempenho das atividades diversas, contribuindo para a melhoria contínua da qualidade da universidade.

A literatura utilizada nesta pesquisa aponta a importância da gestão estratégica de pessoas nessa nova ordem mundial, sendo a função de pessoal que se interessa pela procura, desenvolvimento, remuneração, integração e manutenção do pessoal de uma organização.

Dentre as limitações desta pesquisa, podem ser citados o acesso restrito às IES, em especial às respectivas áreas de $\mathrm{RH}$ devido à política de confidencialidade dos programas e a oscilação da disponibilidade dos docentes pesquisadores e gestores para as entrevistas. Além disso, cabe ressaltar que a peculiaridade de cada IES e a abordagem para o Estado de São Paulo dificultam a generalização das conclusões para os demais programas.

Ainda que existam práticas estratégicas em algumas das instituições pesquisadas, como as que envolvem remuneração por resultados, planos de carreira, cursos para aperfeiçoamento das competências dos pesquisadores, supõem-se que essas práticas não estão atreladas aos planos estratégicos das instituições, sendo consideradas específicas do programa. Como tendência, os estudos apontam para a continuidade dessa incompreensão, na medida em que novas exigências da CAPES acontecem e impõem mudanças nos regimentos internos das IES.

\section{REFERÊNCIAS}

ARMSTRONG, M. Armstrong`s Handbook of human resource management practice. 11 ed. London: Kogan Page, 2009.

BALDUCCI, D. \& KANANAE, R. Relevância da gestão de pessoas no clima organizacional de uma empresa de engenharia. Boletim - Academia Paulista de Psicologia, São Paulo, v.27, p. 06-07, 2007.

BARNEY, J. Firm resources and sustained competitive advantage. Journal of management. V. 17, n. 1, p. 99-120. 1991.

BARRETO, S.T.M.L. \& COSTA, K. B. Estratégias de Gestão de Pessoas. In: Marras, P. J. (org.). Gestão estratégica de Pessoas Conceitos e Tendências. Local: Editora Saraiva, 2010.

REAd | Porto Alegre - Edição 78 - Nº 2 - maio/agosto 2014 - p. 371-396 
Paschoal Palombino Primo, Eduardo de Camargo Oliva \& Edson Keyso de Miranda Kubo

BERNARDES, J. F. As políticas de recursos humanos e suas influências na gestão universitária. In: Colóquio Internacional sobre Gestão Universitária na América do Sul, Buenos Aires, AR, 2003.

BIANCHI, G. P. M. E. Alinhando Estratégia de Negócios e Gestão de Pessoas para obtenção de Vantagem Competitiva. (Dissertação de mestrado). Universidade de São Paulo, SP, Brasil, 2008.

BOHLANDER, G. \& SNELL, S. Administração de Recursos Humanos. I 4. Ed. São Paulo: Congage Learning, 2009.

BOSQUETTI, M. A. Gestão de pessoas, estratégia e performance organizacional: um estudo internacional de casos múltiplos. (Tese de doutorado). FEA/USP, São Paulo, SP, Brasil, 2009.

BOSQUETTI, M. A., \& ALBUQUERQUE, L. G. Gestão estratégica de pessoas: visão do RH x visão dos clientes. XXIX Encontro da ANPAD (EnANPAD), 2005, Brasília. Anais..

Brasília, XXXII EnANPAD, 2005.

BOXALL, P., \& PURCELL, J. Estratégia e Gestão de Recursos Humanos. $2^{\circ}$ Ed. New York: Palgrave MacMillan, 2007.

BOXALL, P.; PURCELL, J. \& WRIGHT, P. The Oxford Handbook of human resource management. New York: Oxford University Press, 2010.

BRASIL, Capes. Coordenação de Aperfeiçoamento de Pessoal de Nível Superior. Disponível em: http://www.capes.gov.br/. Acesso em 06.6.2011.

CRESWELL, J. W. Projeto de Pesquisa, métodos qualitativo, quantitativo e misto. Porto Alegre, Artmed, 2007.

COMBS, C. J., LIU, Y., HALL, A., \& KETCHEN, D. How much do high-performance work practices. A meta-analysis of their effects on organizational performance. Personnel Psychology, v. 59, n.3, p. 501-528, 2006.

EBOLI, M. O. Desenvolvimento das pessoas e a educação corporativa. In: Fleury, M. T. L. et al (org). As pessoas na organização. 12 Ed. São Paulo: Gente, p.185-216. 2002.

REAd | Porto Alegre - Edição 78 - Nº 2 - maio/agosto 2014 - p. 371-396 
Gestão estratégica de pessoas para pesquisadores em administração nas universidades privadas

FREITAS, W. R. DE S. Gestão de Recursos Humanos: análise das melhores práticas adotadas pelas Universidades Estaduais Paulistas. São Paulo. Dissertação (mestrado em Engenharia de Produção). Faculdade de Engenharia de Bauru da Universidade Estadual Paulista "Júlio de Mesquita Filho", 2010.

GARCIA, M. (ORG.) Gestão profissional em Instituições Privadas de ensino superior: um guia de sobrevivência: para mantenedoras, acionistas, reitores, pró-reitores, diretores, coordenadores, gerentes e outros gestores institucionais. Espírito Santo: Ed. Hoper, 2006.

GIBBS, G. Análise de Dados Qualitativos: Porto Alegre. Artimed, 2009.

GIL, A. C. Métodos e Técnicas de Pesquisa Social. 6 ed. São Paulo, Atlas, 2010.

GODOI, C. K.; SILVA, A. B. DA \& BANDEIRA DE M. R. Pesquisa Qualitativa em Estudos Organizacionais: paradigmas, estratégias e métodos. São Paulo: Ed. Saraiva, 2006.

GRILLO, A. N. Gestão de Pessoas: princípios que mudam a Administração Universitária. Florianópolis: UFSC/CAD, 2001.

HANASHIRO, D. M.; TEIXEIRA, M. L. M. \& ZACARELLI, L. M. Gestão do fator humano: uma visão baseada em Stakeholders. $2^{\text {a }}$ ed. São Paulo: Saraiva, 2008.

KISTE, G. Gestão de Recursos Humanos nas áreas técnico - administrativas de Universidades Privadas da Região Leste da Cidade de São Paulo. (Dissertação de mestrado). Universidade Cidade de São Paulo, SP, Brasil, 2001.

LACOMBE, B. M. B. Avaliação e mensuração de resultados em gestão de pessoas e a relação com o desempenho organizacional: um estudo com as maiores empresas brasileiras (Relatório de Pesquisa/02/2006), São Paulo, SP, EAESP, Fundação Getúlio Vargas, 2006.

LACOMBE, B. M. B. \& CHU, R. A. Políticas e práticas de gestão de pessoas: as abordagens estratégicas e institucionais. Revista de Administração de Empresas, v.1 n. 48, 2008.

LEITE, N. P. \& ALBUQUERQUE, L. G. Gestão Estratégica de Pessoas: conceito, evolução e visão. In: Albuquerque, L. G.: Leite, N. Pitombo (Org.) Gestão de Pessoas - Perspectivas Estratégicas. São Paulo: Atlas, 2009.

REAd | Porto Alegre - Edição 78 - Nº 2 - maio/agosto 2014 - p. 371-396 
Paschoal Palombino Primo, Eduardo de Camargo Oliva \& Edson Keyso de Miranda Kubo

MARRAS, J. P. Administração da Remuneração. São Paulo: Thomson Learning, 2002.

MARTINS, C. B. Pós-Graduação no contexto do ensino superior brasileiro. In: MOHRY, L. et al. (orgs.) Universidade em Questão, 1. Brasília: UnB, 2003. p. 175-206.

MONTEIRO, O. Talentos - Busca e Retenção. In: Jean Pierre Marras (Org.). Gestão Estratégica de Pessoas. São Paulo. Saraiva, 2010.

MUELLER, F. Human resource as strategic assets: an evolutionary resource-based theory. Journal of Management Studies, v. 33, n. 6, p.757-785, 1996.

NASCIMENTO, L.F.\& PESSOA, R.W.A. Qualidade de Vida no Trabalho: uma questão de responsabilidade social. Revista Eletrônica de Administração, v. 13, n. 3, p. 17-23, 2007.

OLIVA, E. C. \& ALBUQUERQUE, L. G. Filosofia e modelo dos programas de remuneração das empresas que aderiram aos níveis diferenciados de governança corporativa da Bovespa. Revista de Gestão da USP, v. 13, n. 2, p. 83, 2006.

QUEIROZ, A. C. S. \& ALBUQUERQUE, L. G. Análise de ambiente organizacional. In Leite, N. P. \& Albuquerque, L. G.. Gestão de pessoas perspectivas estratégicas. São Paulo: Ed. Atlas, p.17-26, 2009.

SANTOS, E, H. A gestão estratégica de recursos humanos numa instituição de ensino superior confessional sem fins lucrativos. (Dissertação de mestrado). UMESP, São Bernardo do Campo, SP, Brasil, 2010.

SILVA, M.L,C. \& FONSECA, S.V. Estruturação da Estrutura Organizacional: o Caso de uma Empresa Familiar. Revista de Administração Contemporânea, v. 14, p. 5, Ed. Especial, 2010.

TOH, S.M.; MORGESON, F.P. \& CAMPION M. A. Human resource configurations: investigating fit with the organizational contexto. American Psychological Association, v. 93, n, 4, p. 864-882, 2008.

TONET, H. C. \& PAZ, M. G. T. Um modelo para o compartilhamento de conhecimento no trabalho. Revista de Administração Contemporânea, v. 10, n. 2, p. 6, 2006. 
Gestão estratégica de pessoas para pesquisadores em administração nas universidades privadas

ULRICH, D. Os Campeões de Recursos Humanos: inovando para obter os melhores resultados. São Paulo: Ed. Futura, p.340, 1998.

VELloso, J. Mestres e Doutores no País. Destinos profissionais e políticas de pósgraduação. Cadernos de Pesquisa, v. 34 n. 123, p. 583-611, 2004.

REAd | Porto Alegre - Edição 78 - Nº 2 - maio/agosto 2014 - p. 371-396 